\title{
Blocking the Nav1.5 channel using eicosapentaenoic acid reduces migration and proliferation of ovarian cancer cells
}

\author{
JUNXIU LIU ${ }^{1 *}$, DAWEI LIU ${ }^{2 *}$, JASMINE J. LIU ${ }^{3}$, CHANG ZHAO $^{4}$, SHUZHONG YAO $^{1}$ and LIANG HONG ${ }^{3}$ \\ Departments of ${ }^{1}$ Obstetrics and Gynecology and ${ }^{2}$ Pathology, The First Affiliated Hospital, Sun Yat-Sen University, Guangzhou, \\ Guangdong 510080, P.R. China; ${ }^{3}$ Department of Medicine, University of Illinois at Chicago, Chicago, IL 60612; \\ ${ }^{4}$ Department of Physiology and Biophysics, University of California, Irvine, CA 92697, USA
}

Received January 17, 2018; Accepted April 17, 2018

DOI: $10.3892 /$ ijo.2018.4437

\begin{abstract}
Activity of the voltage-gated Nav1.5 sodium channel has been reported to be involved in cell proliferation, cancer invasion and gene expression. In addition, eicosapentaenoic acid (EPA) has recently been suggested to inhibit ovarian cancer cell growth and suppress tumor metastasis. The present study aimed to explore the association between EPA, the Nav1.5 sodium channel and ovarian cancer cells. Using patch-clamp technique and RNA interference approaches, sodium currents were recorded in epithelial ovarian cancer cells, and it was confirmed that the Nav1.5 channel carried the sodium currents. Furthermore, EPA effectively inhibited sodium currents in a dose-dependent manner, shifted the steady-state inactivation curve of sodium currents to the hyperpolarizing direction and reduced sodium window currents. In addition, EPA induced a shift in the inactivation curve in a dose-dependent manner. Inhibition of the sodium channel, either by EPA or by Nav1.5 knockdown, attenuated ovarian cancer cell migration and proliferation. To the best of our knowledge, the present study is the first to conduct sodium current recording in ovarian cancer cells, and revealed that EPA may inhibit Nav1.5-mediated ovarian cancer cell migration and growth. These findings not only present a potential prognostic biomarker for ovarian
\end{abstract}

Correspondence to: Dr Liang Hong, Department of Medicine, University of Illinois at Chicago, $840 \mathrm{~S}$ Wood Street, Chicago, IL 60612, USA

E-mail: hong2004@uic.edu

Dr Shuzhong Yao, Department of Obstetrics and Gynecology, The First Affiliated Hospital, Sun Yat-Sen University, 58 Zhongshan 2nd Road, Guangzhou, Guangdong 510080, P.R. China

E-mail: yaoshuzh@mail.sysu.edu.cn

*Contributed equally

Abbreviations: EPA, eicosapentaenoic acid; TTX, tetrodotoxin

Key words: Nav1.5 voltage-gated sodium channel, ovarian neoplasms, eicosapentaenoic acid, voltage-gated sodium channel blockers, ion channels cancer, but also provide a strategy towards the development of novel pharmacological treatments for patients with ovarian cancer.

\section{Introduction}

Ovarian cancer is one of the most common types of cancer among women worldwide, resulting in $>14,000$ cases of mortality each year (1). Epithelial ovarian cancer is the most common type of ovarian cancer, which has the highest mortality rate of all gynecological malignancies. This high mortality rate is largely due to the lack of an effective biomarker; in addition, it is difficult to diagnose patients at the early stage of the disease and most patients are diagnosed at advanced stages (2-4).

The Nav1.5 channel protein is a member of the voltagegated sodium channel family (5). It is the predominant sodium channel in cardiomyocytes and permeates sodium currents to initiate the action potential duration in the heart (6). Previous studies have reported that Nav1.5 channels are expressed in various types of cancer cells, including leukemia (7), prostate cancer (8), breast cancer (9) and colon cancer (10), in which they serve roles in $\mathrm{T}$ lymphocyte invasiveness, prostate cell pathological differentiation, breast tumor metastasis and colon cancer transcriptional activity. Furthermore, growing evidence has suggested that the Nav1.5 channel is implicated in ovarian cancer development $(11,12)$, thus suggesting that small molecule-induced inhibition of this channel may lead to a novel pharmacological treatment.

Eicosapentaenoic acid (EPA) is a long-chain n-3 polyunsaturated fatty acid, which has been revealed to reduce blood lipid levels and lessen inflammation. In addition, EPA has been reported to balance metabolism, inhibit proliferation and induce apoptosis (13). EPA may also inhibit human atrial sodium currents in a concentration-dependent manner in cardiomyocytes; these effects may contribute to atrial fibrillation treatment (14). Recently, EPA has been reported to suppress ovarian cancer cell growth, reduce cancer metastasis and kill ovarian cancer cells (15); however, the underlying mechanism by which EPA attenuates ovarian cancer invasion and cell proliferation remains to be elucidated.

The present study demonstrated that EPA may inhibit Nav1.5 sodium currents in the epithelial ovarian cancer cell 
lines TOV112D, A2780 and SKOV3, and that EPA alters the gating process of Nav1.5 and abolishes channel activity in these cells. Furthermore, the effects of EPA on Nav1.5-mediated ovarian cancer cell migration and growth were determined.

\section{Materials and methods}

Cell culture. TOV112D, A2780 and SKOV3 ovarian cancer cell lines were purchased from the American Type Culture Collection (Manassas, VA, USA). TOV112D cells were cultured in a 1:1 mixture of M199 and MCDB105 media, supplemented with $10 \%$ (wt/vol) fetal bovine serum (FBS) (both from Sigma-Aldrich; Merck KGaA, Darmstadt, Germany). A2780 and SKOV3 cells were maintained in RPMI-1640 medium (Gibco; Thermo Fisher Scientific, Inc., Waltham, MA, USA), supplemented with $10 \%$ (wt/vol) FBS. In addition, A2780 cells were supplemented with $50 \mu \mathrm{g} / \mathrm{ml}$ insulin (Sigma-Aldrich; Merck KGaA). All cells were maintained at $37^{\circ} \mathrm{C}$ in an incubator containing $5 \%(\mathrm{vol} / \mathrm{vol}) \mathrm{CO}_{2}$.

Electrophysiological measurements and analysis. Patchclamp measurements were performed in whole-cell configuration using an Axopatch 200B amplifier controlled by pClamp10 software through an Axon Digidata 1440A system (all from Molecular Devices, LLC, Sunnyvale, CA, USA) $(16,17)$. The extracellular solution contained $140 \mathrm{mM}$ $\mathrm{NaCl}, 4.7 \mathrm{mM} \mathrm{KCl}, 1.2 \mathrm{mM} \mathrm{MgCl} 2,2.5 \mathrm{mM} \mathrm{CaCl}_{2}, 10 \mathrm{mM}$ HEPES and $11 \mathrm{mM}$ glucose, adjusted to $\mathrm{pH} 7.4$ with $\mathrm{NaOH}$. The intracellular solution contained $140 \mathrm{mM} \mathrm{CsCl}, 2 \mathrm{mM}$ $\mathrm{MgCl}_{2}, 0.1 \mathrm{mM} \mathrm{CaCl} 2,1.1 \mathrm{mM}$ EGTA and $10 \mathrm{mM}$ HEPES, adjusted to $\mathrm{pH} 7.2$ with $\mathrm{CsOH}$. The sodium currents were activated by depolarization to $-10 \mathrm{mV}$ for $50 \mathrm{msec}$ from a holding potential of $-110 \mathrm{mV}$. To test steady-state activation, the sodium currents were measured from a holding potential of $-110 \mathrm{mV}$ to test potentials ranging between -110 to $+70 \mathrm{mV}$ in $10 \mathrm{mV}$ steps, followed by repolarization to $-110 \mathrm{mV}$. To test steady-state inactivation, currents were elicited to $0 \mathrm{mV}$ following prepulses ranging between -140 and $0 \mathrm{mV}$ in $10 \mathrm{mV}$ steps for 200 msec. EPA was purchased from Sigma-Aldrich; Merck KGaA and dissolved in ethanol to obtain a stock concentration of $10 \mathrm{mM}$; butylated-hydroxyanisole was added at a ratio of $0.005 \% \mathrm{w} / \mathrm{v}$ to the stock solution, which was then stored at $-80^{\circ} \mathrm{C}(18)$. EPA was added to the extracellular solution at the desired final concentrations (1-200 $\mu \mathrm{M})$, and the sodium currents were recorded before and after the addition of EPA, or after EPA washout. All measurements were performed at $22 \pm 2^{\circ} \mathrm{C}$. Pipettes had 2-4 M 2 access resistance $(19,20)$. Current densities were calculated according to whole-cell current amplitude and capacitance values obtained from the amplifier following electronic subtraction of the capacitive transients.

Dose-responses of channel inhibition were fitted by the Hill equation, as previously described (21): $\%_{i}=\%_{i, \max }[B]^{h} /\left(I C_{50}{ }^{h}+[B]^{h}\right)$, where $\%_{i, \max }$ is the maximal percentage of channel inhibition by blocker $B, h$ is the Hill coefficient and $I C_{50}$ is the concentration of an inhibitor required for $50 \%$ inhibition. Steady-state activation G-V were fitted by the Boltzmann equation, as described previously (22): $G / G_{\max }=1 /\left(1+\exp \left(V_{I / 2}-V\right) / K\right)$, where $G / G_{\max }$ is the relative conductance normalized by the maximal conductance, $V_{l / 2}$ is the potential of half activation, $V$ is test pulse, and $k$ is the
Boltzmann coefficient. Steady-state inactivation I-V were fitted by the Boltzmann equation: $I / I_{\max }=1 /\left(1+\exp \left(V_{I / 2}-V\right) / K\right)$.

Western blot analysis. Ovarian cancer cells were rinsed twice with ice-cold PBS, and were then harvested and lysed with lysis buffer $\left(50 \mathrm{mM}\right.$ Tris- $\mathrm{HCl}, 150 \mathrm{mM} \mathrm{NaCl}, 0.02 \% \mathrm{NaN}_{3}$, $1 \%$ Nonidet $\mathrm{P}-40,0.1 \%$ sodium dodecyl sulfate, $0.5 \%$ sodium deoxycholate and $1 \%$ protease inhibitor cocktail; Sigma-Aldrich; Merck KGaA). Protein concentration was quantified using the bicinchoninic acid assay (Beyotime Institute of Biotechnology, Haimen, China) and proteins ( $25 \mu \mathrm{g} / \mathrm{lane})$ were separated by $6 \%$ SDS-PAGE and transferred to polyvinylidene fluoride membranes (EMD Millipore, Bedford, MA, USA). Membranes were blocked at room temperature for $1 \mathrm{~h}$ in $5 \%$ non-fat milk dissolved in Tris-buffered saline containing Tween-20 (150 mM NaCl, $50 \mathrm{mM}$ Tris, 0.1\% Tween-20; pH 7.5), and were incubated with rabbit anti-human Nav1.5 (1:1,000, ASC-013; Alomone Labs, Jerusalem, Israel) and rabbit anti-GAPDH (1:1,000, \#5174; Cell Signaling Technology, Inc., Danvers, MA, USA) primary antibodies at $4^{\circ} \mathrm{C}$ overnight. Subsequently, membranes were incubated with the goat anti-rabbit horseradish peroxidase-conjugated secondary antibodies $(1: 10,000$, ab6721; Abcam, Cambridge, UK) for $1.5 \mathrm{~h}$ at room temperature. Bands were detected by chemiluminescence assay (Beyotime Institute of Biotechnology) and were semi-quantified using ImageJ version 1.4.3 (National Institutes of Health, Bethesda, MD, USA).

Small interfering (si)RNA transfection. SKOV3 ovarian cancer cells were transfected with siRNA directed against sodium voltage-gated channel $\alpha$ subunit 5 (SCN5A) mRNA (Nav1.5targeting siRNA; forward, 5'-GAACGGCACCUCUGAUGU GTT-3' and reverse, 5'-CACAUCAGAGGUGCCGUUCTT-3') or scramble siRNA-A (forward, 5' GCAACAAUGUGCGUC CUGGTT-3' and reverse, 5'-CCAGGACGCACAUUGUUG CTT-3'), which was used as a control (SiCtl). siRNAs were purchased from Santa Cruz Biotechnology, Inc. (Dallas, TX, USA). Cells ( $80 \%$ confluence) were transfected with 20 or $40 \mathrm{nM}$ siRNA using Lipofectamine ${ }^{\circledR}$ RNAiMAX (Invitrogen; Thermo Fisher Scientific, Inc.), according to the manufacturer's protocol. Subsequently, the migration and cell proliferation assays, and the patch clamp technique, were performed $24 \mathrm{~h}$ post-transfection.

Nav1.5 transfection. The pRc/CMV plasmid containing the sequence of the human Nav1.5 channel was kindly provided by Dr Alfred L. George Jr (Northwestern University, Chicago, IL, USA). The pRc/CMV-hNav1.5 plasmid contains a $6.1 \mathrm{~kb}$ cDNA sequence encoding the human voltage-gated sodium channel Nav1.5 (SCN5A gene product) inserted into the NotI (5') and $\mathrm{XbaI}\left(3^{\prime}\right)$ sites of the mammalian expression vector, pRc/CMV (5.4 kb). Plasmids containing cDNA encoding human Nav1.5 channels (pRc/CMV-hNav1.5) and green fluorescent protein (GFP; pRc/CMV-GFP) were co-transfected into 293T cells (cat. no. CRL-3216; American Type Culture Collection), which do not possess endogenous Nav1.5 channels. Cells $(80 \%$ confluence) were transfected with $1 \mu \mathrm{g} / \mu 1$ plasmids using Lipofectamine ${ }^{\circledR} 3000$ reagent (Invitrogen; Thermo Fisher Scientific, Inc.), according to the manufacturer's protocol. The cells were then cultured for $24 \mathrm{~h}$ in Dulbecco's modified 
A

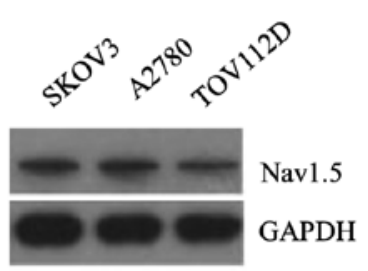

B

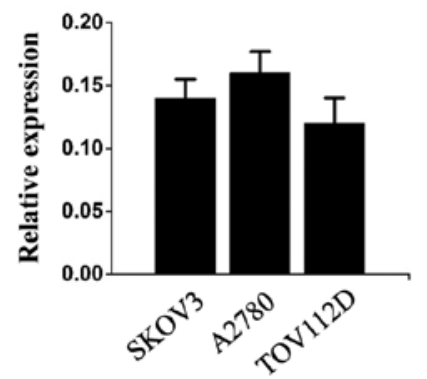

C $\begin{array}{lll}\text { SKOV3 } & \text { A2780 } & \text { TOV112D }\end{array}$
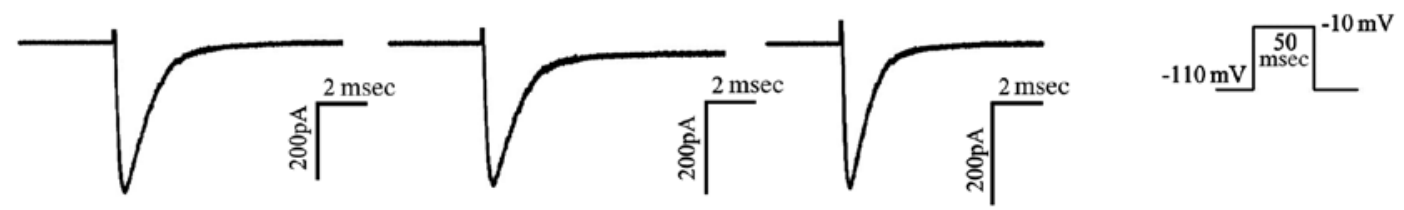

D
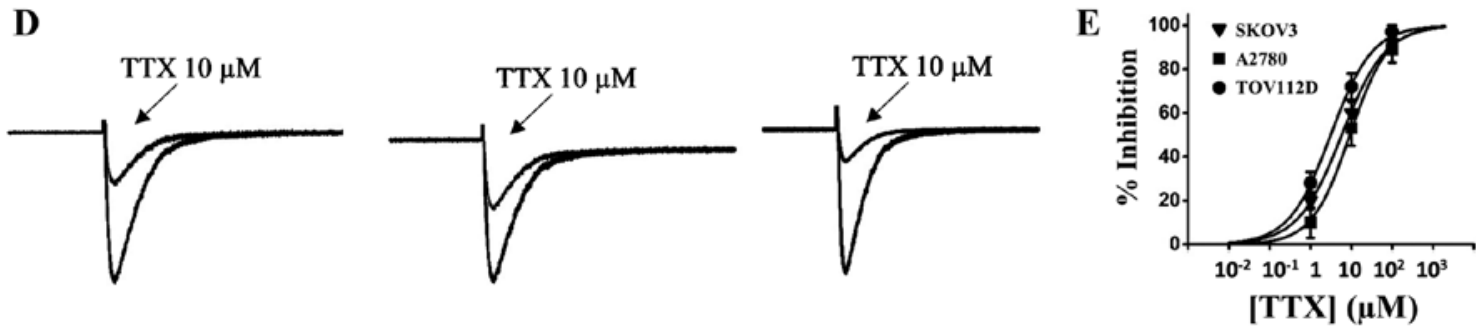

Figure 1. Characterization of voltage-gated sodium currents in ovarian cancer cells. (A and B) Western blot analysis of Nav1.5 protein expression in the ovarian cancer cell lines SKOV3, A2780 and TOV112D ( $\mathrm{n=7}$ ). (C) Voltage-gated sodium currents recorded in SKOV3, A2780 and TOV112D cells. Currents were activated by depolarization to $-10 \mathrm{mV}$ for $50 \mathrm{msec}$ from a holding potential of $-110 \mathrm{mV}$. (D) Sodium currents recorded in ovarian cancer cells prior to and following the addition of $10 \mu \mathrm{M}$ TTX. (E) Dose-dependent effects of TTX on sodium current inhibition ( $\mathrm{n}=5$ for each concentration; data are presented as the means \pm standard error of the mean), curves are Hill fits of the data points. TTX, tetrodotoxin.

Eagle's medium supplemented with $10 \%$ FBS (both from Gibco; Thermo Fisher Scientific, Inc.). Patch clamp experiments were conducted $24-48 \mathrm{~h}$ after $293 \mathrm{~T}$ cells were reseeded on coverslips in 6-well plates containing RPMI-1640 medium. A coverslip with $293 \mathrm{~T}$ cells was placed in a recording chamber containing bath solution on the stage of a fluorescence microscope (Nikon Corporation, Tokyo, Japan), and the transfected cells were identified by the fluorescent signal emitted from GFP (data not shown).

Migration assay. SKOV3 cells were seeded onto 24-well plates $(10,000$ cells/well). For the wound-healing assay, scratch lesions were created on confluent SKOV3 cells using a $10 \mu \mathrm{l}$ pipette tip. Wounded cultures were incubated at room temperature for $36 \mathrm{~h}$, and three randomly selected fields at the lesion border were subsequently examined by inverted phase contrast microscopy (IX73; Olympus Corporation, Tokyo, Japan) in order to assess cell migration.

Cell proliferation assay. Cell Counting kit-8 (CCK-8) assay (Dojindo Molecular Technologies, Inc., Kumamoto, Japan) was used to study SKOV3 cell proliferation, according to the manufacturer's protocol. SKOV3 cells were seeded at a density of $5 \times 10^{3}$ cells/well in 96-well plates, after which $10 \mu \mathrm{l} \mathrm{CCK}-8$ solution was added to each well. Absorbance was measured at $450 \mathrm{~nm}$ using a multiplate reader (Lambda Bio-20; Beckman Coulter, Inc., Brea, CA, USA). Cell viability was expressed as a percentage of that of the control (untreated) cells.
Data analysis. All data are presented as the means \pm standard error of the mean. The $n$ value denotes the number of independent experiments conducted, unless otherwise stated. Significance between means was determined using either the two-tailed Student's paired t-test or one-way analysis of variance with Dunnett's multiple comparisons test. $\mathrm{P}<0.05$ was considered to indicate a statistically significant difference.

\section{Results}

Characterization of voltage-gated sodium channel Nav1.5 currents in ovarian cancer cells. The voltage-gated sodium channel Nav1.5 has been implicated in ovarian cancer (12), the present study detected Nav1.5 expression in the epithelial ovarian cancer cell lines TOV112D, A2780 and SKOV3. The results of a western blot analysis indicated that Nav1.5 channel protein was expressed in the three ovarian cancer cells (Fig. 1A and B). Although the voltage-gated sodium channels have been associated with ovarian cancer development, to the best of our knowledge, the functional sodium currents have not been examined in ovarian cancer cells $(11,12)$. Using whole cell patch-clamp configuration, the present study observed fast inactivation currents in ovarian cancer cells (Fig. 1C). The currents elicited by depolarization to $-10 \mathrm{mV}$ were further measured prior to and after the addition of the specific voltage-gated sodium channel blocker tetrodotoxin (TTX); Sigma-Aldrich; Merck KGaA) to the bath solution; currents were partially inhibited by $10 \mu \mathrm{M}$ TTX (Fig. 1D). TTX had $\mathrm{IC}_{50}$ values of 5.8, 9.2 and $3.1 \mu \mathrm{M}$ in 
A

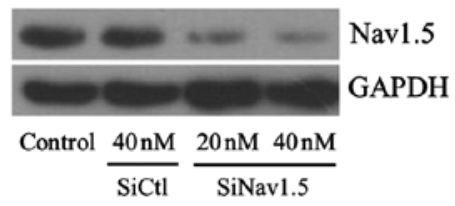

D

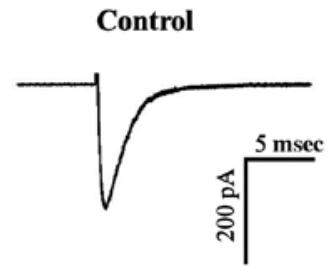

B

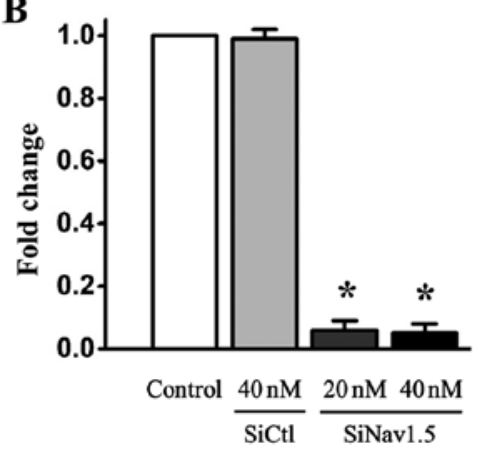

C

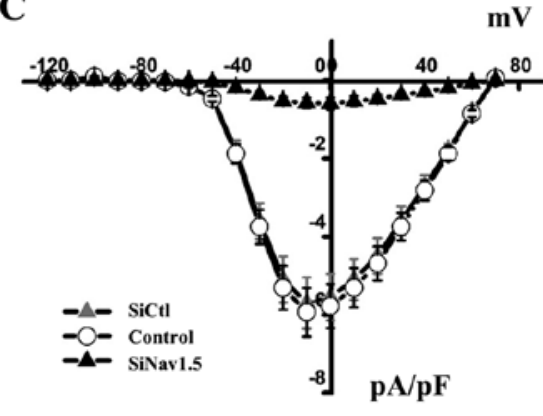

SiCtl

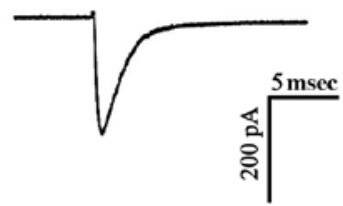

SiNav1.5

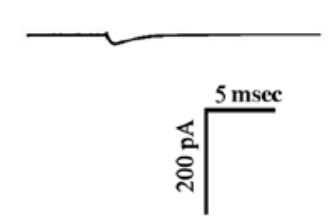

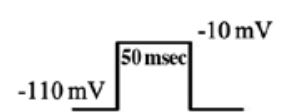

Figure 2. Effects of Nav1.5 knockdown on sodium currents in SKOV3 cells. (A and B) Western blot analysis of Nav1.5 expression in SKOV3 cells transfected with $40 \mathrm{nM} \mathrm{SiCtl}$, or 20 or $40 \mathrm{nM} \mathrm{SiNav1.5} \mathrm{(n=5).} \mathrm{P}<0.05$ vs. SiCtl. (C) Normalized I-V plot of currents recorded from cells in the various groups (control, $40 \mathrm{nM} \mathrm{SiCtl}$ and $40 \mathrm{nM}$ SiNav1.5) ( $\mathrm{n}=7$ for each group; data are presented as the means \pm standard error of the mean). (D) Examples of sodium currents in the control, SiCtl and SiNav1.5 cell groups. Currents were activated by depolarization to $-10 \mathrm{mV}$ with $50 \mathrm{msec}$ duration from a holding potential of $-110 \mathrm{mV}$. SiCtl, control siRNA; SiNav1.5 Nav1.5-specific siRNA; siRNA, small interfering RNA.

SKOV3, A2780, and TOV112D ovarian cancer cells, respectively (Fig. 1E and Table I). Since the $\mathrm{IC}_{50}$ values were in the micromolar range, it was suggested that these cell lines were of the TTX-resistant subtype (23).

Effects of Nav1.5 knockdown on sodium currents. To further analyze sodium currents in ovarian cancer cells, the RNA interference approach was used to knockdown Nav1.5 expression in SKOV3 cancer cells. Transfection with Nav1.5 siRNA resulted in a significant reduction in the protein expression levels of Nav1.5, whereas SiCtl did not alter Nav1.5 expression (Fig. 2A and B). The reduction in Nav1.5 protein expression was associated with $>90 \%$ reduction of the maximal currents recorded when the cells were depolarized to $-10 \mathrm{mV}$ (Fig. 2C and D). These results indicated that the sodium currents were predominantly carried by the Nav1.5 channel, and that Nav1.5 channels are functionally expressed in ovarian cancer cells.

EPA functionally inhibits Nav1.5 sodium currents in ovarian cancer cells. After examining Nav1.5 channel currents in ovarian cancer cells, the present study aimed to determine whether EPA exerted effects on them (Fig. 3). EPA was previously reported to block the Nav1.5 channel in cardiomyocytes (14), and to inhibit ovarian cancer cell growth and reduce cancer metastasis (15). The present study hypothesized that EPA may affect the Nav1.5 channel in ovarian cancer cells; the results indicated that treatment with $15 \mu \mathrm{M}$ EPA blocked $\sim 60 \%$ sodium currents in SKOV3 cancer cells (Fig. 3A, B and E), and this inhibition could be completely reversed following EPA washout (Fig. 3C and D). Furthermore, $15 \mu \mathrm{M}$ EPA blocked sodium currents to similar extents in A2780 and TOV112D cancer cells (Fig. 3F and G). Various concentrations of EPA were then used to generate a dose-response curve; the $\mathrm{IC}_{50}$ values for EPA in SKOV3, A2780 and TOV112D cells were $11.8,19.6$ and $18.1 \mu \mathrm{M}$, respectively (Fig. $3 \mathrm{H}$ and Table I). These results indicated that EPA may effectively block Nav1.5 sodium currents in ovarian cancer cells. Subsequently, the present study aimed to explore the potential mechanism by which EPA inhibits Nav1.5 currents.

EPA shifts the steady-state inactivation curve of sodium currents in a hyperpolarizing direction. Previous studies demonstrated that EPA induces Nav1.5 channels to enter an inactive state and stabilizes the channel, thus resulting in a reduction of sodium currents $(24,25)$. The present study investigated the effects of EPA on SKOV3 cancer cells (Fig. 4); the results indicated that $15 \mu \mathrm{M}$ EPA shifted the steady-state inactivation of sodium currents by $\sim 20 \mathrm{mV}$ to the hyperpolarizing direction (Fig. 4A and $\mathrm{C}$ and Table II), whereas it had almost no effect on channel activation (Fig. 4B and C and Table III). The window currents were obtained by plotting the area where steady-state inactivation and activation overlap; EPA significantly reduced the Nav1.5 sodium window currents (Fig. 4D). In addition, the shifts of inactivation induced by EPA, along with the rise of EPA concentration, were gradually enhanced to the hyperpolarizing direction, indicating that the shift of steady-state inactivation is EPA dose-dependent (Fig. 5 and Table II). In the other two ovarian cancer cells (A2780 and TOV112D cells), $15 \mu \mathrm{M}$ EPA also altered steady-state inactivation curves to the hyperpolarizing direction, and did not significantly alter steady-state activation curves (Fig. 6 and Tables II and III). Subsequently, the present study transfected 293T cells with Nav1.5 cDNA; the results revealed that EPA hyperpolarized the slow inactivation curve of Nav1.5 channels and reduced Nav1.5 channel availability, which are consistent with the results in ovarian cancer cells (Fig. 7). In conclusion, these data suggested that EPA may enhance sodium channel 
A

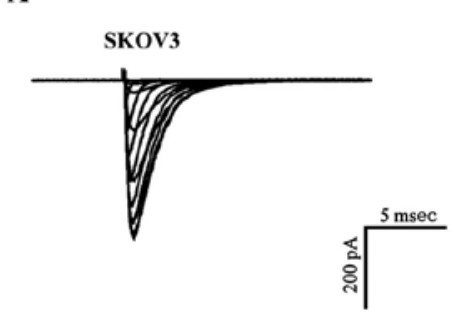

B

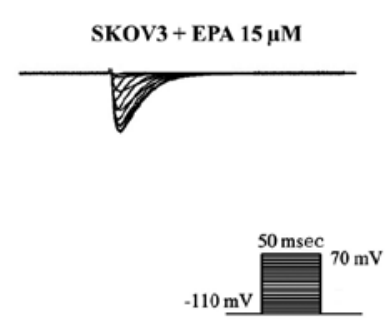

C pA

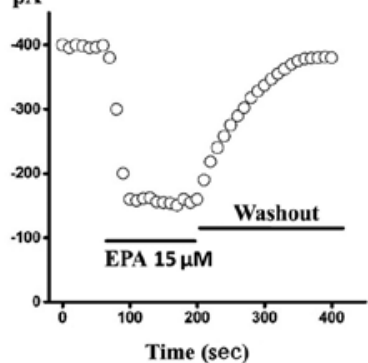

D

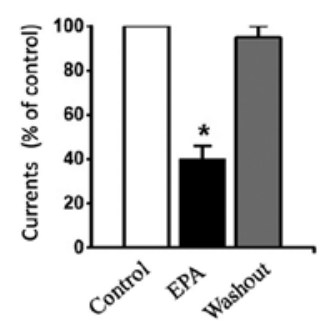

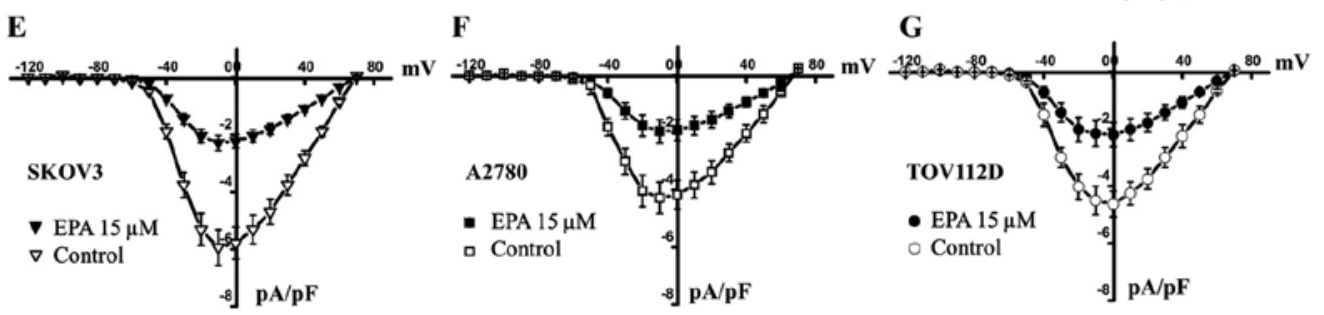

$\mathbf{H}$

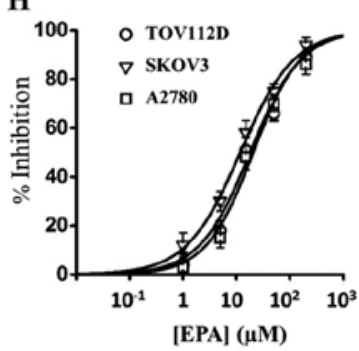

Figure 3. Inhibition of sodium currents by EPA. Voltage-gated sodium currents recorded in SKOV3 ovarian cancer cells (A) prior to and (B) following the addition of $15 \mu \mathrm{M} \mathrm{EPA}$ into the bath solution. Currents were measured from a holding potential of $-110 \mathrm{mV}$ to test potentials ranging from -110 to $+70 \mathrm{mV}$ in $10 \mathrm{mV}$ steps, followed by repolarization to $-110 \mathrm{mV}$. (C) Time courses of inhibition produced by $15 \mu \mathrm{M}$ EPA. Sodium currents were evoked every $10 \mathrm{sec}$ with $50 \mathrm{msec}$ duration pulses to $-10 \mathrm{mV}$ from a holding potential of $-110 \mathrm{mV}$. (D) Bars indicate stable currents shown in (C) $(\mathrm{n}=6)$. " $\mathrm{P}<0.05$ vs. the control. Representative normalized peak I-V plot of currents recorded from (E) SKOV3, (F) A2780 and (G) TOV112D ovarian cancer cells prior to and after treatment with $15 \mu \mathrm{M}$ EPA ( $n=6$ for each cell line; data are presented as the means \pm standard error of the mean). (H) Dose-dependent effects of EPA on sodium current inhibition ( $\mathrm{n}=6$ for each concentration; data are presented as the means \pm standard error of the mean), curves are Hill fits of the data points. EPA, eicosapentaenoic acid.

Table I. $\mathrm{IC}_{50}$ values, as fitted by the Hill equation, of TTXor EPA-induced channel inhibition in ovarian cancer cells. Sodium currents were recorded in independent cultures.

\begin{tabular}{llrl}
\hline Inhibitor & Cell type & $\mathrm{IC}_{50}(\mu \mathrm{M})$ & $\mathrm{n}$ \\
\hline TTX & SKOV3 & $5.8 \pm 0.4$ & 5 \\
TTX & A2780 & $9.2 \pm 0.7$ & 5 \\
TTX & TOV112D & $3.1 \pm 0.3$ & 5 \\
EPA & SKOV3 & $11.8 \pm 1.0$ & 6 \\
EPA & A2780 & $19.6 \pm 1.8$ & 6 \\
EPA & TOV112D & $18.1 \pm 1.2$ & 6
\end{tabular}

EPA, eicosapentaenoic acid; $\mathrm{IC}_{50}$, half maximal inhibitory concentration; TTX, tetrodotoxin.

inactivation and stabilize the inactivation gate of the channel, thus indicating that EPA-induced reductions in sodium currents may be due to more channels remaining in the inactivated state post-activation.

Inhibition of the Nav1.5 channel attenuates SKOV3 cell migration. The present study also aimed to examine the function of Nav1.5 during the process of ovarian cancer development. The Nav1.5 channel has been reported to promote cancer cell invasion (26); therefore, inhibition of this channel was expected to reduce cell migration. The present study used a wound-healing assay to investigate the effects of either Nav1.5 knockdown or Nav1.5 functional inhibition by EPA on SKOV3 ovarian cancer cell migration. The cells were divided into five groups: Group 1, control; group 2, cells transfected with
Table II. $V_{1 / 2}$ of voltage dependence of steady-state inactivation of sodium channels prior to and after treatment with EPA. Sodium currents were recorded in independent cultures.

\begin{tabular}{llrr}
\hline Group & Cell line & $V_{1 / 2}(\mathrm{mV})$ & $\mathrm{n}$ \\
\hline Control & SKOV3 & $-67.3 \pm 8.4$ & 7 \\
Control & A2780 & $-78.0 \pm 3.4$ & 8 \\
Control & TOV112D & $-70.6 \pm 3.4$ & 6 \\
EPA $15 \mu \mathrm{M}$ & SKOV3 & $-99.0 \pm 5.8$ & 7 \\
EPA $15 \mu \mathrm{M}$ & A2780 & $-91.1 \pm 3.2$ & 8 \\
EPA $15 \mu \mathrm{M}$ & TOV112D & $-85.8 \pm 4.1$ & 6 \\
EPA $1 \mu \mathrm{M}$ & SKOV3 & $-78.1 \pm 3.7$ & 10 \\
EPA $5 \mu \mathrm{M}$ & SKOV3 & $-87.4 \pm 3.5$ & 9 \\
EPA $50 \mu \mathrm{M}$ & SKOV3 & $-101.4 \pm 7.5$ & 9 \\
EPA $200 \mu \mathrm{M}$ & SKOV3 & $-106.9 \pm 4.5$ & 10 \\
\hline
\end{tabular}

Table III. $V_{1 / 2}$ values from Boltzmann fits of voltage dependence of activation of sodium channels prior to and after treatment with EPA. Sodium currents were recorded in independent cultures.

\begin{tabular}{llll}
\hline Group & Cell line & $V_{1 / 2}(\mathrm{mV})$ & $\mathrm{n}$ \\
\hline Control & SKOV3 & $-31.1 \pm 3.4$ & 7 \\
Control & A2780 & $-38.0 \pm 3.3$ & 8 \\
Control & TOV112D & $-26.5 \pm 4.3$ & 6 \\
EPA $15 \mu \mathrm{M}$ & SKOV3 & $-32.6 \pm 3.3$ & 7 \\
EPA $15 \mu \mathrm{M}$ & A2780 & $-34.9 \pm 4.0$ & 8 \\
EPA $15 \mu \mathrm{M}$ & TOV112D & $-29.8 \pm 4.4$ & 6 \\
\hline
\end{tabular}




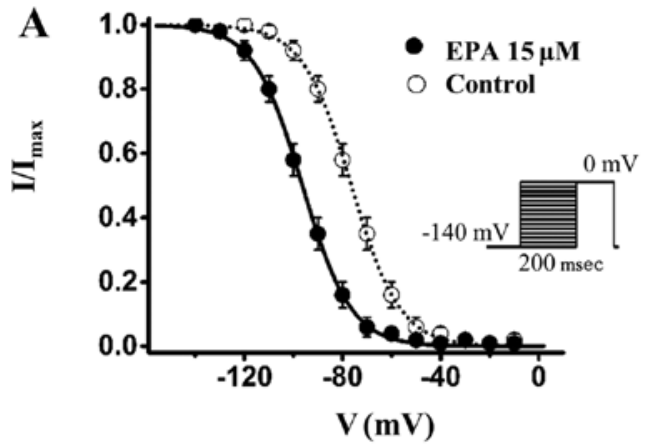

C

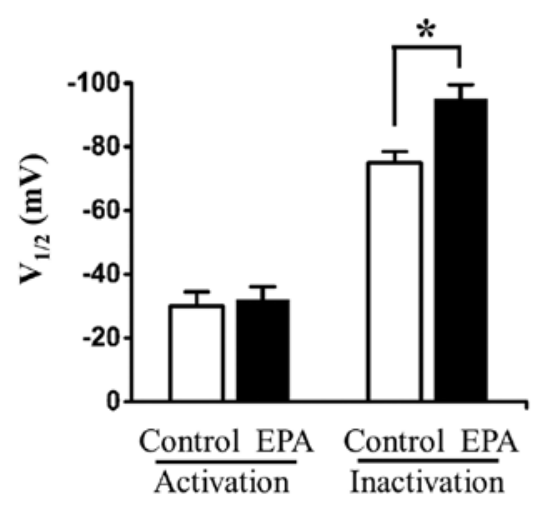

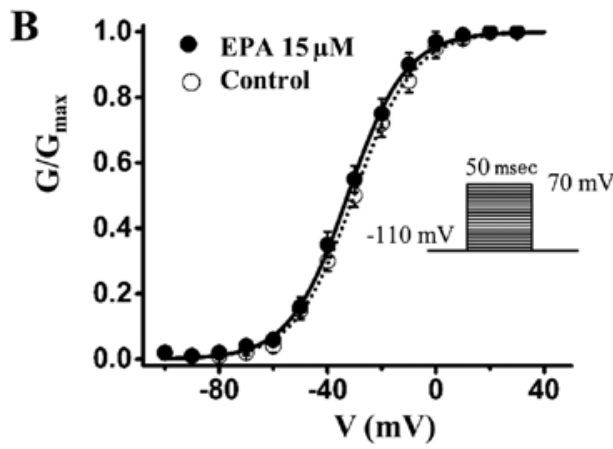

D

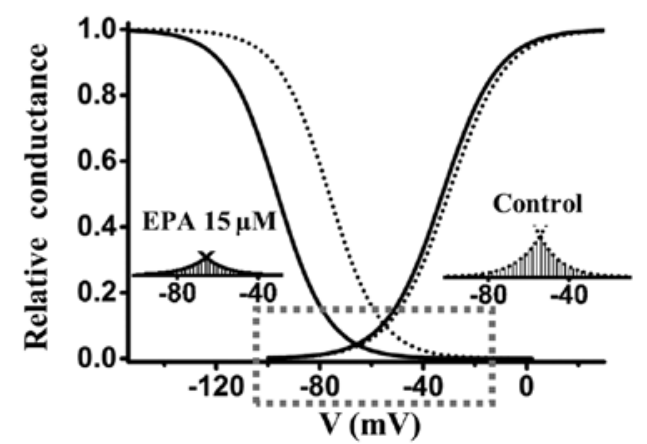

Figure 4. Effects of EPA on steady-state inactivation and activation of the sodium currents in SKOV3 ovarian cancer cells. (A) Steady-state inactivation curve of sodium currents prior to and after treatment with $15 \mu \mathrm{M} \mathrm{EPA}$. Currents were elicited to $0 \mathrm{mV}$ following prepulses ranging between -140 and $0 \mathrm{mV}$ in $10 \mathrm{mV}$ steps for $200 \mathrm{msec}(\mathrm{n}=7$; data are presented as the means \pm standard error of the mean). (B) Steady-state activation curve of the Nav1.5 sodium channel prior to and after treatment with $15 \mu \mathrm{M}$ EPA. Currents were measured from a holding potential of $-110 \mathrm{mV}$ to test potentials ranging between $-110 \mathrm{and}+70 \mathrm{mV}$ in $10 \mathrm{mV}$ steps ( $\mathrm{n}=7$; data are presented as the means \pm standard error of the mean). (A and B) Curves are Boltzmann fits of the data points. (C) Steady-state activation and inactivation $V_{1 / 2}$ prior to and after treatment with $15 \mu \mathrm{M} \mathrm{EPA} \mathrm{(} \mathrm{n}=7$; data are presented as the means \pm standard error of the mean). ${ }^{*} \mathrm{P}<0.05 \mathrm{vs}$. the control. (D) Plots of current availability by the Boltzmann fits of inactivation curve in (A) and activation curve in (B), gray dashed box indicates window currents. Right inset shows sodium window currents prior to treatment with EPA (control), left inset shows sodium window currents after treatment with $15 \mu \mathrm{M}$ EPA. EPA, eicosapentaenoic acid.

A

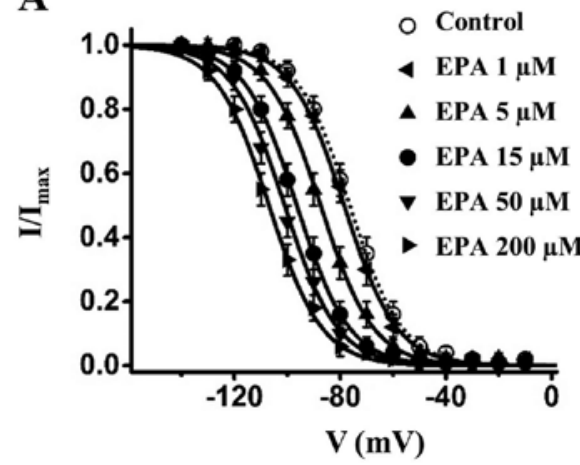

B

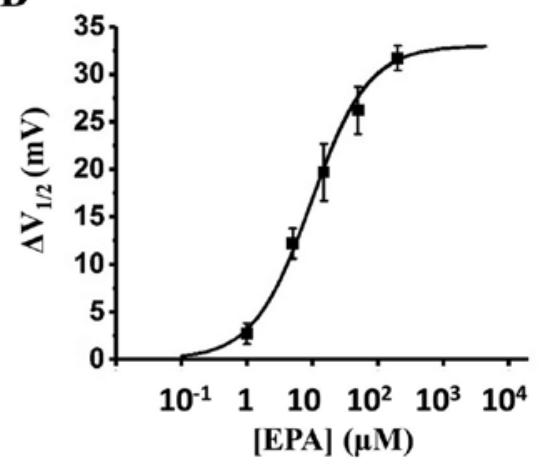

Figure 5. Steady-state inactivation shifts are dependent on EPA concentration. (A) Steady-state inactivation curve of the sodium currents in SKOV3 ovarian cancer cells prior to and after treatment with various EPA concentrations. (B) Association between shifts of inactivation $\left(\Delta V_{1 / 2}\right)$ and EPA concentration $(\mathrm{n}=7$ for $15 \mu \mathrm{M}$ EPA, $\mathrm{n}=9$ for 5 and $50 \mu \mathrm{M}$ EPA, $\mathrm{n}=10$ for 1 and $200 \mu \mathrm{M} \mathrm{EPA}$; data are presented as the means \pm standard error of the mean). EPA, eicosapentaenoic acid.

Nav1.5 siRNA; group 3, cells transfected with SiCtl; group 4 , cells treated with $200 \mu \mathrm{M} \mathrm{EPA}$; group 5, cells transfected with Nav1.5 siRNA and treated with $200 \mu \mathrm{M}$ EPA (Fig. 8). The results demonstrated that EPA was able to inhibit SKOV3 cell migration in a dose-dependent manner (Fig. 8C), and migration was significantly reduced in Nav1.5 siRNA-transfected cells compared with in SiCtl cells (Fig. 8A and B). Notably, the migration of Nav1.5 siRNA-transfected cells was not further reduced by $200 \mu \mathrm{M}$ EPA, thus indicating that the impaired invasion of these cells was due to the absence of Nav1.5 activities (Fig. 8B). These results suggested that the Nav1.5 channel may have a critical role in ovarian cancer migration, and the effects of EPA on cell migration were due to the blockade of Nav1.5 sodium channels.

EPA inhibits SKOV3 cell proliferation via Nav1.5. Using the CCK-8 assay, it was revealed that EPA inhibited the proliferation of SKOV3 cells in a dose-dependent manner (Fig. 9A). 
A

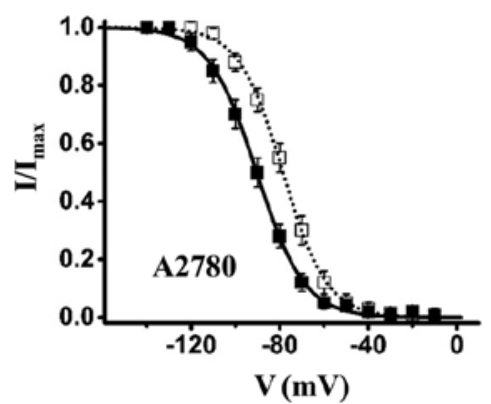

D

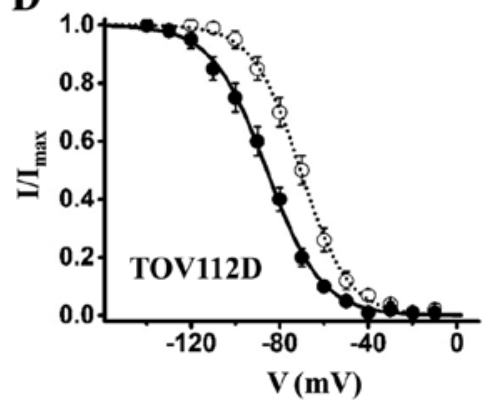

B
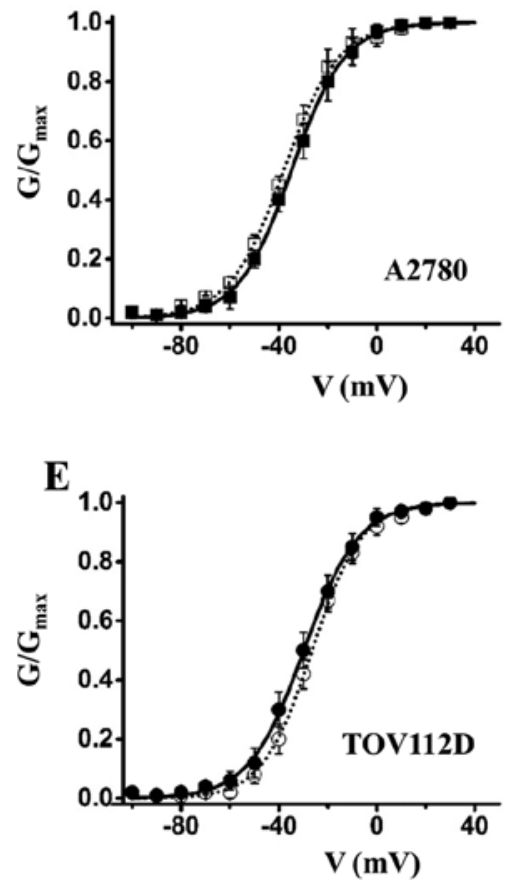

C

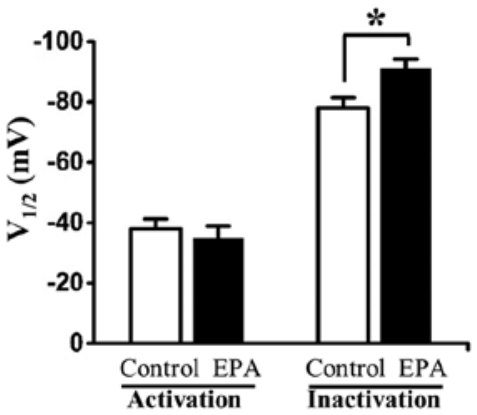

$\mathbf{F}$

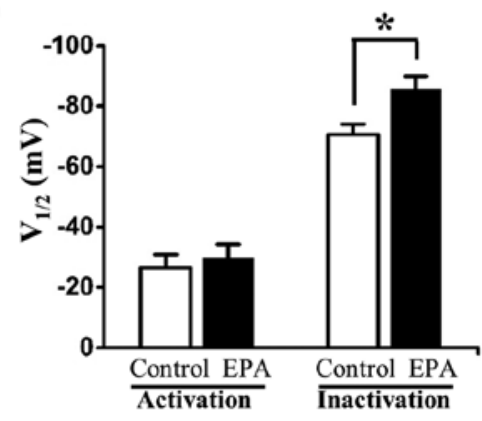

Figure 6. Effects of EPA on the steady-state inactivation of sodium currents in A2780 and TOV112D ovarian cancer cells. (A) Steady-state inactivation curve and (B) activation curve of sodium currents prior to and after treatment with $15 \mu \mathrm{M} \mathrm{EPA}$ in A2780 cells. (C) Steady-state activation and inactivation $V_{l / 2}$ prior to and after treatment with $15 \mu \mathrm{M}$ EPA in A2780 cells ( $\mathrm{n}=8)$. ${ }^{*} \mathrm{P}<0.05$ vs. the control. (D) Steady-state inactivation curve and (E) activation curve of sodium currents prior to and after treatment with $15 \mu \mathrm{M}$ EPA in TOV112D cells. (F) Steady-state activation and inactivation $V_{1 / 2}$ prior to and after treatment with $15 \mu \mathrm{M}$ EPA in TOV112D cells ( $\mathrm{n}=6)$. ${ }^{\mathrm{P}}<0.05$ vs. the control. EPA, eicosapentaenoic acid.

A

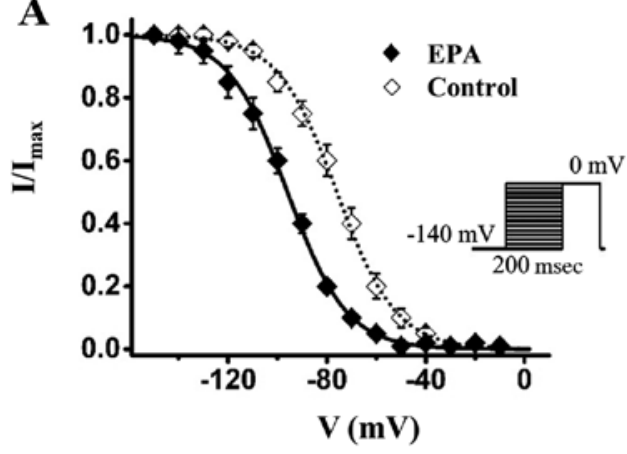

C

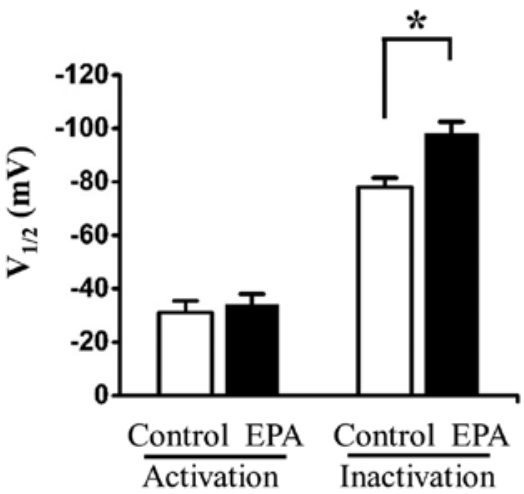

B

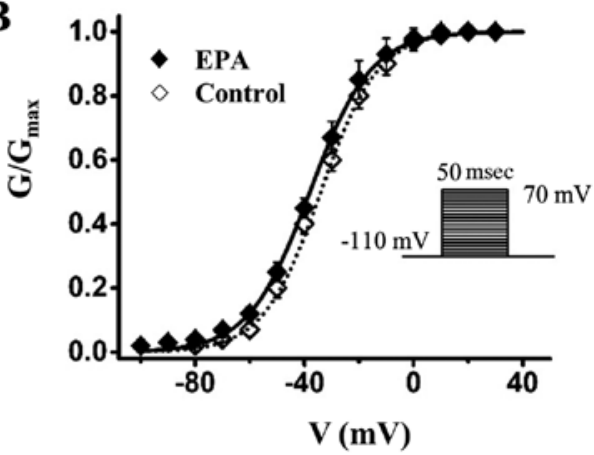

D

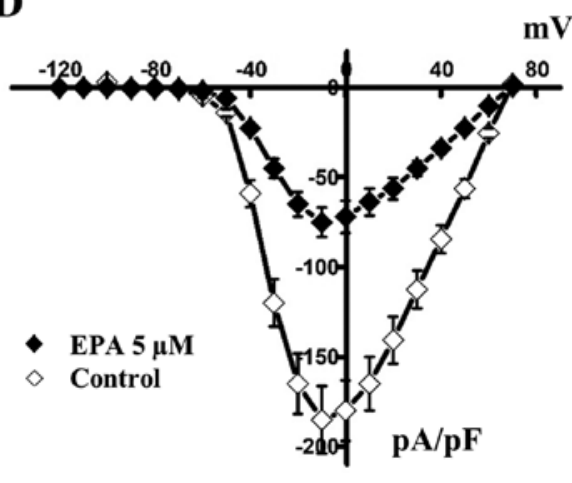

Figure 7. Effects of EPA on steady-state inactivation and activation of the Nav1.5 currents in 293T cells. (A) Steady-state inactivation curve of Nav1.5 currents prior to and after treatment with $5 \mu \mathrm{M}$ EPA. Currents were elicited to $0 \mathrm{mV}$ following prepulses ranging between -140 and $0 \mathrm{mV}$ in $10 \mathrm{mV}$ steps for $200 \mathrm{msec}$ ( $\mathrm{n}=6$; data are presented as the means \pm standard error of the mean). (B) Steady-state activation curve of the Nav1.5 sodium channel prior to and after treatment with $5 \mu \mathrm{M}$ EPA. Currents were measured from a holding potential of $-110 \mathrm{mV}$ to test potentials ranging between -110 and $+70 \mathrm{mV}$ in $10 \mathrm{mV}$ steps (n=6; data are presented as the means \pm standard error of the mean). (A and B) Curves are Boltzmann fits of the data points. (C) Steady-state activation and inactivation $V_{1 / 2}$ prior to and after treatment with $5 \mu \mathrm{M}$ EPA ( $\mathrm{n}=6$; data are presented as the means \pm standard error of the mean). ${ }^{*} \mathrm{P}<0.05 \mathrm{vs}$. the control. (D) Normalized I-V plot of Nav1.5 currents recorded from cells prior to and after treatment with $5 \mu \mathrm{M} \mathrm{EPA} \mathrm{(} \mathrm{n}=6$; data are presented as the means \pm standard error of the mean). EPA, eicosapentaenoic acid. 
A
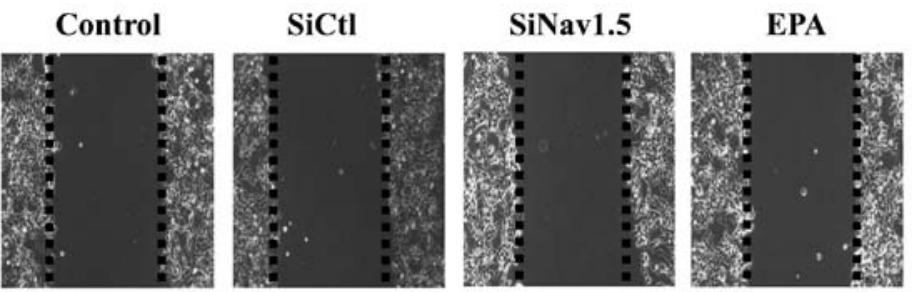

EPA + SiNav1.5

$36 \mathrm{~h}$
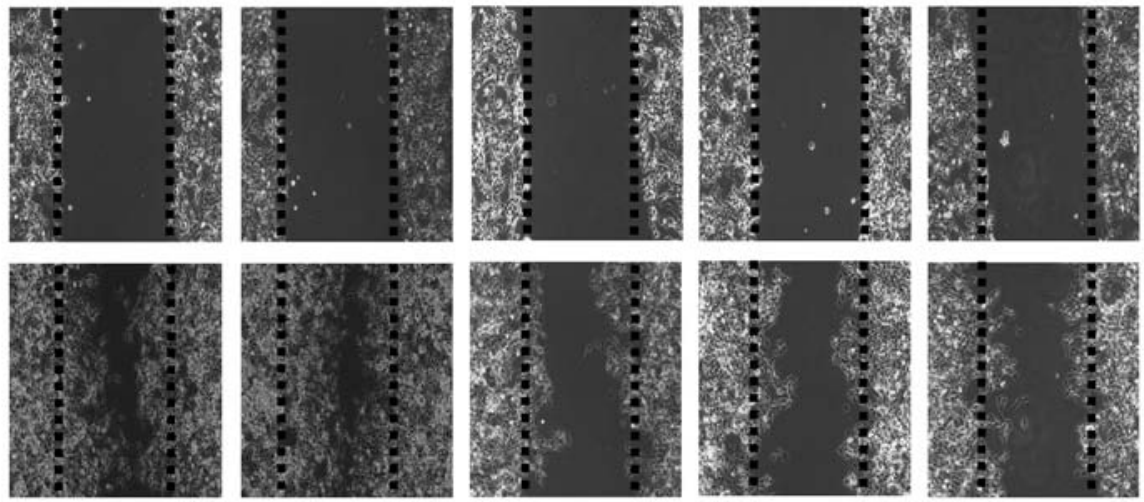

B

C
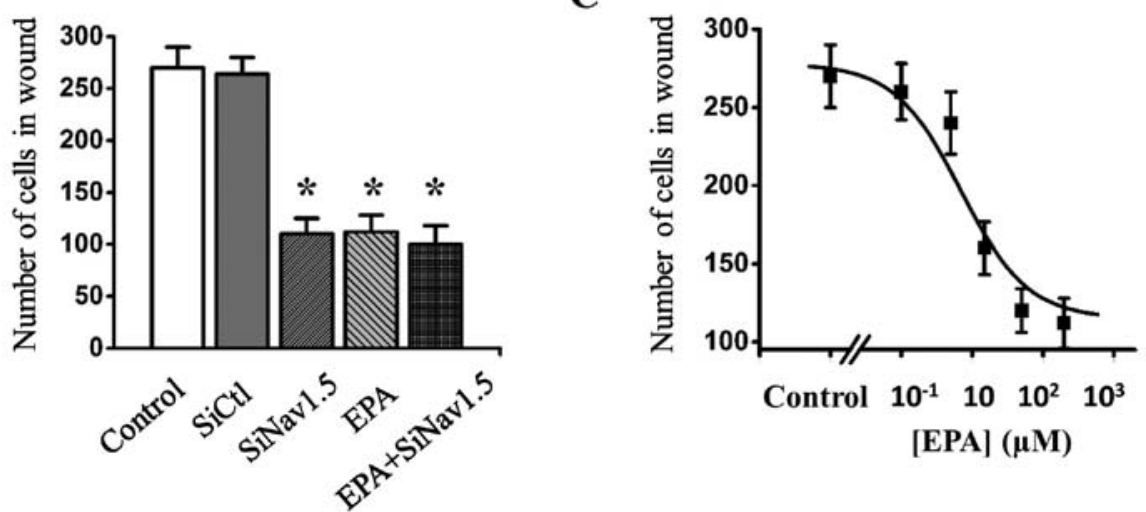

Figure 8. Inhibition of the Nav1.5 channel attenuates SKOV3 cell migration. (A) Representative images (magnification, $\mathrm{x} 10$ ) of in vitro wound healing at $36 \mathrm{~h}$

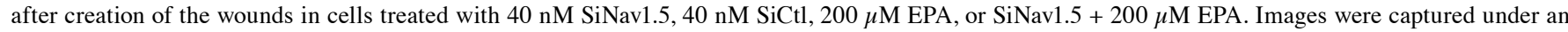
inverted phase contrast microscope. (B) Bars indicate results shown in (A) ( $\mathrm{n}=6$ for each group; data are presented as the means \pm standard error of the mean). ${ }^{*} \mathrm{P}<0.05$ vs. the control and SiCtl. (C) EPA inhibited SKOV3 cell migration in a dose-dependent manner ( $\mathrm{n}=7$ for each concentration; data are presented as the means \pm standard error of the mean). Curves are Hill fits of the data points. EPA, eicosapentaenoic acid; SiCtl, control siRNA; SiNav1.5 Nav1.5-specific siRNA; siRNA, small interfering RNA.

$\mathbf{A}$

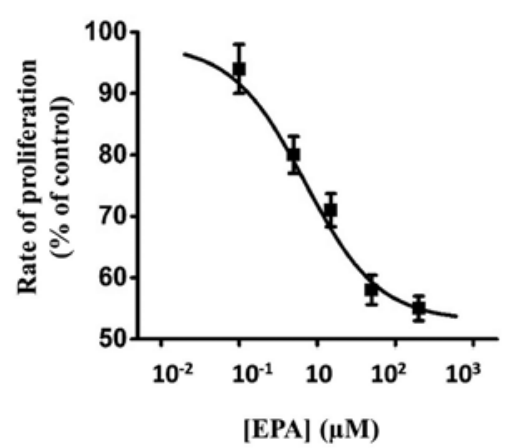

B

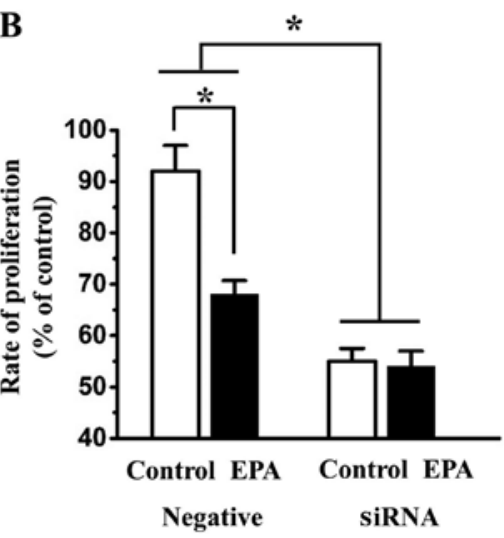

Figure 9. Effects of EPA on SKOV3 cell proliferation. (A) EPA inhibited proliferation of SKOV3 cells in a dose-dependent manner ( $\mathrm{n}=7$ for each concentration; data are presented as the means \pm standard error of the mean). Curves are Hill fits of the data points. (B) Effects of Nav1.5 siRNA on the inhibitory effects of $15 \mu \mathrm{M}$ EPA on cell proliferation in SKOV3 cells ( $\mathrm{n}=6$; data are presented as the means \pm standard error of the mean). "P<0.05 vs. the control, or as indicated. EPA, eicosapentaenoic acid; siRNA, small interfering RNA.

Knockdown of Nav1.5 in SKOV3 cells resulted in a marked decrease in the inhibitory effect of $15 \mu \mathrm{M}$ EPA on SKOV3 cell proliferation. In addition, $15 \mu \mathrm{M}$ EPA alone still inhibited SKOV3 cell proliferation in SiCtl-transfected cells (Fig. 9B). Collectively, these data indicated that inhibition of Nav1.5 by EPA may reduce ovarian cell proliferation.

\section{Discussion}

To the best of our knowledge, the present study is the first to record voltage-gated sodium currents in ovarian cancer cells; the currents were further characterized to be carried by the Nav1.5 channel. In addition, EPA effectively inhibited sodium 
currents in the ovarian cancer cells, and shifted the steadystate inactivation of voltage-gated sodium currents to the hyperpolarizing direction, thus resulting in reduced window currents and blockade of the channel. The functional inhibition of Nav1.5 sodium channels by EPA attenuated ovarian cancer cell migration and proliferation.

EPA is a member of the family of long-chain n-3 polyunsaturated fatty acids. It is usually used as a nutritional supplement to treat cancer-associated cachexia (27). Previous studies reported that EPA exerts a direct effect on cancer development, and induces cancer apoptosis, suppresses cell migration and affects cancer metastasis $(15,28,29)$. EPA has been hypothesized to regulate the apoptotic signaling pathway, inhibit tumor migration and enhance the effects of anticancer drugs. EPA was previously reported to block endogenous Nav1.5 channels in cardiomyocytes; EPA was able to induce Nav1.5 channels to enter an inactive state, thus resulting in a reduction of sodium currents $(14,18)$. In addition, another study identified position N406 of the Nav1.5 channel as the key interacting site with EPA, and an N406 mutation (N406K) significantly decreases the inhibitory effects of EPA on Nav1.5 sodium currents (24). The present study revealed that EPA reduced Nav1.5-mediated ovarian cancer cell migration and growth, and observed that EPA blocked sodium currents in ovarian cancer cells in a dosedependent manner. EPA IC $_{50}$ values were measured and it was revealed that EPA was able to inhibit sodium currents in various ovarian cancer cells within similar concentration ranges; this is consistent with previous findings regarding the effects of EPA on Nav1.5 channels in cardiomyocytes (14). Furthermore, this study indicated that EPA shifted the steady-state inactivation curve of sodium currents to a hyperpolarizing direction; however, it had almost no effect on the steady-state activation curve, thus resulting in a decrease of Nav1.5 channel window currents.

The window currents are defined as the currents that flux through voltage-gated sodium channels in a narrow voltage range, in which steady-state inactivation and activation states overlap (30). At transmembrane potentials beyond this window, channels cannot generate any sodium currents due to the channels being either in a closed state or an inactivated state. Therefore, the window current serves an important role in the function of voltage-gated sodium channels (31). The sodium channel window currents usually control action potential shape in excitable cells, such as cardiomyocytes and neurons; however, upregulated window currents have been reported to trigger arrhythmias or dysfunctional excitationcontraction coupling $(32,33)$. The present study demonstrated that EPA effectively inhibited window currents carried by the Nav1.5 channel in ovarian cancer cells, and reduced cancer cell migration and proliferation.

It has been reported that a neonatal splice variant of the Nav1.5 channel (nNav1.5) is predominantly expressed in the highly metastatic MDA-MB-231 breast cancer cell line; therefore, $\mathrm{nNav1.5}$ has been proposed as a marker with clinical potential for the management of metastatic breast cancer (34). Compared with the adult variant Nav1.5 (aNav1.5), nNav1.5 exhibits a 6-amino acid substitution in the S3 and S4 loop in domain I, and one amino acid substitution in S4 of domain I (35). This structural difference produces unique properties for nNav1.5. For example, in nNav1.5 voltage-dependence of activation is shifted in the depolarized direction, and is much slower to open and close. The $V_{1 / 2}$ of activation for $\mathrm{nNav1.5}$ is $-19 \mathrm{mV}$, whereas for aNav1.5 it is $-28 \mathrm{mV}$ (35). The present results indicated that the $V_{1 / 2}$ of activation for Nav1.5 was between -26 and $-38 \mathrm{mV}$ in ovarian cancer cells, thus suggesting that being different from breast cancer cells, aNav1.5 may be the predominant Nav1.5 in ovarian cancer cells.

It is well known that ion channels have important roles in the growth and migration of cancer cells (36-41), and cell proliferation and invasion are crucial hallmarks for cancer development (42). In addition, the association between cancer proliferation and resting potential has been supported by studies in breast cancer cells, hepatocellular carcinoma cells, fibrosarcoma cells and ovarian cancer cells (43). It was revealed that cancer cells have low resting potential and tend to be more depolarized than normal cells. The resting potential of ovarian tumor cells was approximately $-10 \mathrm{mV}$, in which most Nav1.5 channels are activated (44). The low resting potential may activate voltage-dependent Nav1.5 channels in ovarian cancer cells and provide an explanation for the mechanism underlying Nav1.5-dependent proliferation of cancer cells. There are several theories regarding how sodium currents contribute to cancer cell growth and tumor invasiveness. One explanation is that sodium ions permeate from the sodium channel, thus leading to the entry of calcium through the sodium-calcium exchanger (NCX), which induces $\mathrm{Ca}^{2+}$-dependent signaling to promote cancer cell invasion and metastatic progression (26). Another theory proposed is that the local sodium concentration is able to activate the $\mathrm{Na}^{+} / \mathrm{H}^{+}$ exchanger (NHE) and enhance $\mathrm{H}^{+}$efflux, consequently leading to increased intracellular alkalinisation and decreased extracellular $\mathrm{pH}$. Increased glycolytic metabolism in cancer cells gives rise to an excessive production of intracellular acidity; therefore, intracellular alkalinisation potentially facilitates cancer metabolism. In addition, a lower extracellular $\mathrm{pH}$ environment activates $\mathrm{pH}$-dependent cathepsin proteases and invadopodia formation, which in turn, may enhance cancer cell invasion (45). In the present study, the sodium currents that promote ovarian cancer cell migration and proliferation were suppressed by EPA treatment or by Nav1.5-targeting siRNA, thus indicating that Nav1.5-mediated sodium currents have crucial roles during the development of ovarian cancer. However, whether Nav1.5 induced $\mathrm{Ca}^{2+}$-dependent signaling by stimulating NCX activity to accelerate ovarian tumor progression, or activated NHE to increase $\mathrm{H}^{+}$efflux, in order to provide a favorable environment for ovarian cancer growth, remain unclear; further studies are required to address these uncertainties.

In conclusion, to the best of our knowledge, the present study was the first to record Nav1.5-mediated sodium currents in ovarian cancer cells; the results revealed that Nav1.5 currents were effectively inhibited by EPA. The mechanism by which EPA blocked the Nav1.5 channel was due to increased inactivation of the Nav1.5 sodium channel, thus resulting in a reduction in window currents and blockade of the channel. These findings highlight the importance of Nav1.5 in cancer development, and may provide novel insights into the development of chemotherapeutics for ovarian cancer. 


\section{Acknowledgements}

The authors would like to thank Dr A.L. George Jr (Northwestern University, Chicago, IL, USA) for the hNav1.5 channel cDNA, Dr D. Zhang (Sun Yat-Sen University, Guangzhou, Guangdong, China) for helpful discussions, and Dr G. Yao (Sun Yat-Sen University, Guangzhou, Guangdong, China) and other members of the laboratory for insightful comments on the manuscript.

\section{Funding}

The present study was supported by the Young Scientists Fund of the National Natural Science. Foundation of China (grant no. 81502226) and the Guangdong Natural Science Foundation (grant no. 2014A030313038).

\section{Availability of data and materials}

All data generated or analyzed during this study are included in this published article.

\section{Authors' contributions}

SY and LH designed the project. JL, DL, JJL and CZ performed research; JL, DL, SY and LH analyzed the data; JL and LH wrote the paper. All authors read and edited the manuscript.

\section{Ethics approval and consent to participate}

Not applicable.

\section{Consent for publication}

Not applicable.

\section{Competing interests}

The authors declare that they have no competing interests.

\section{References}

1. Smith RA, Andrews KS, Brooks D, Fedewa SA, ManassaramBaptiste D, Saslow D, Brawley OW and Wender RC: Cancer screening in the United States, 2017: A review of current American Cancer Society guidelines and current issues in cancer screening. CA Cancer J Clin 67: 100-121, 2017.

2. Jelovac D and Armstrong DK: Recent progress in the diagnosis and treatment of ovarian cancer. CA Cancer J Clin 61: 183-203, 2011.

3. Chen M, Yao S, Cao Q, Xia M, Liu J and He M: The prognostic value of Ki67 in ovarian high-grade serous carcinoma: An 11-year cohort study of Chinese patients. Oncotarget 8: 107877-107885, 2016.

4. Asher V, Khan R, Warren A, Shaw R, Schalkwyk GV, Bali A and Sowter HM: The Eag potassium channel as a new prognostic marker in ovarian cancer. Diagn Pathol 5: 78, 2010.

5. Yu FH and Catterall WA: Overview of the voltage-gated sodium channel family. Genome Biol 4: 207, 2003.

6. Liu M, Yang KC and Dudley SC Jr: Cardiac sodium channel mutations: Why so many phenotypes? Nat Rev Cardiol 11: 607-615, 2014.

7. Fraser SP, Diss JK, Lloyd LJ, Pani F, Chioni AM, George AJ and Djamgoz MB: T-lymphocyte invasiveness: Control by voltagegated $\mathrm{Na}^{+}$channel activity. FEBS Lett 569: 191-194, 2004.
8. Shan B, Dong M, Tang H, Wang N,Zhang J, Yan C, Jiao X, Zhang H and Wang C: Voltage-gated sodium channels were differentially expressed in human normal prostate, benign prostatic hyperplasia and prostate cancer cells. Oncol Lett 8: 345-350, 2014.

9. Fraser SP, Diss JK, Chioni AM, Mycielska ME, Pan H, Yamaci RF, Pani F, Siwy Z, Krasowska M, Grzywna Z, et al: Voltage-gated sodium channel expression and potentiation of human breast cancer metastasis. Clin Cancer Res 11: 5381-5389, 2005.

10. House CD, Vaske CJ, Schwartz AM, Obias V, Frank B, Luu T, Sarvazyan N, Irby R, Strausberg RL,Hales TG, et al: Voltage-gated $\mathrm{Na}^{+}$channel SCN5A is a key regulator of a gene transcriptional network that controls colon cancer invasion. Cancer Res 70: 6957-6967, 2010.

11. Frede J, Fraser SP, Oskay-Özcelik G, Hong Y, Ioana Braicu E, Sehouli J, Gabra H and Djamgoz MB: Ovarian cancer: Ion channel and aquaporin expression as novel targets of clinical potential. Eur J Cancer 49: 2331-2344, 2013.

12. Gao R, Shen Y, Cai J, Lei M and Wang Z: Expression of voltagegated sodium channel alpha subunit in human ovarian cancer. Oncol Rep 23: 1293-1299, 2010.

13. Brinton EA and Mason RP: Prescription omega-3 fatty acid products containing highly purified eicosapentaenoic acid (EPA). Lipids Health Dis 16: 23, 2017.

14. Li GR, Sun HY, Zhang XH, Cheng LC, Chiu SW, Tse HF and Lau CP: Omega-3 polyunsaturated fatty acids inhibit transient outward and ultra-rapid delayed rectifier $\mathrm{K}^{+}$currents and $\mathrm{Na}^{+}$ current in human atrial myocytes. Cardiovasc Res 81: 286-293, 2009.

15. Wan XH, Fu X and Ababaikeli G: Docosahexaenoic acid induces growth suppression on epithelial ovarian cancer cells more effectively than eicosapentaenoic acid. Nutr Cancer 68: 320-327, 2016.

16. Pathak MM, Tran T, Hong L, Joós B, Morris CE and Tombola F: The Hv1 proton channel responds to mechanical stimuli. J Gen Physiol 148: 405-418, 2016.

17. Hong L and Tombola F: Allostery: A lipid two-step. Nat Chem Biol 12: 202-203, 2016.

18. Leifert WR, McMurchie EJ and Saint DA: Inhibition of cardiac sodium currents in adult rat myocytes by $n-3$ polyunsaturated fatty acids. J Physiol 520: 671-679, 1999.

19. Alkhalil A, Hong L, Nguitragool W and Desai SA: Voltagedependent inactivation of the plasmodial surface anion channel via a cleavable cytoplasmic component. Biochim Biophys Acta 1818: 367-374, 2012.

20. Hong L, Wang G and Guan Y: Involvement of volume-regulated Cl- current in myocardial hypertrophy. Chinese Pharmacological Bulletin 23: 990-993, 2007.

21. Hong L, Singh V, Wulff H and Tombola F: Interrogation of the intersubunit interface of the open Hv1 proton channel with a probe of allosteric coupling. Sci Rep 5: 14077, 2015.

22. Kim IH, Hevezi P, Varga C, Pathak MM, Hong L, Ta D, Tran CT, Zlotnik A, Soltesz I and Tombola F: Evidence for functional diversity between the voltage-gated proton channel Hv1 and its closest related protein HVRP1. PLoS One 9: e105926, 2014.

23. Zimmer T, Haufe V and Blechschmidt S: Voltage-gated sodium channels in the mammalian heart. Glob Cardiol Sci Pract 2014: 449-463, 2014.

24. Xiao YF, Ke Q, Wang SY, Auktor K, Yang Y, Wang GK, Morgan JP and Leaf A: Single point mutations affect fatty acid block of human myocardial sodium channel alpha subunit $\mathrm{Na}^{+}$ channels. Proc Natl Acad Sci USA 98: 3606-3611, 2001.

25. Xiao YF, Ma L, Wang SY, Josephson ME, Wang GK, Morgan JP and Leaf A: Potent block of inactivation-deficient $\mathrm{Na}^{+}$channels by $\mathrm{n}-3$ polyunsaturated fatty acids. Am J Physiol Cell Physiol 290: C362-C 370, 2006.

26. Besson P, Driffort V, Bon É, Gradek F, Chevalier S and Roger S: How do voltage-gated sodium channels enhance migration and invasiveness in cancer cells? Biochim Biophys Acta 1848: 2493-2501, 2015.

27. Pappalardo G, Almeida A and Ravasco P: Eicosapentaenoic acid in cancer improves body composition and modulates metabolism. Nutrition 31: 549-555, 2015.

28. Sharma A, Belna J, Espat J, Rodriguez G, Cannon VT and Hurteau JA: Effects of omega-3 fatty acids on components of the transforming growth factor beta-1 pathway: implication for dietary modification and prevention in ovarian cancer. Am J Obstet Gynecol 200: 516.e1-6, 2009.

29. Sharma A, Belna J, Logan J, Espat J and Hurteau JA: The effects of Omega-3 fatty acids on growth regulation of epithelial ovarian cancer cell lines. Gynecol Oncol 99: 58-64, 2005. 
30. Attwell D, Cohen I, Eisner D, Ohba M and Ojeda C: The steady state TTX-sensitive ('window') sodium current in cardiac Purkinje fibres. Pflugers Arch 379: 137-142, 1979.

31. Frenz CT, Hansen A, Dupuis ND, Shultz N, Levinson SR, Finger TE and Dionne VE: NaV1.5 sodium channel window currents contribute to spontaneous firing in olfactory sensory neurons. J Neurophysiol 112: 1091-1104, 2014.

32. Moreau A, Krahn AD, Gosselin-Badaroudine P, Klein GJ, Christé G, Vincent Y, Boutjdir M and Chahine M: Sodium overload due to a persistent current that attenuates the arrhythmogenic potential of a novel LQT3 mutation. Front Pharmacol 4: 126, 2013.

33. Janssen LJ: T-type and L-type $\mathrm{Ca}^{2+}$ currents in canine bronchial smooth muscle: Characterization and physiological roles. Am J Physiol 272: C1757-C1765, 1997.

34. Brackenbury WJ, Chioni AM, Diss JK and Djamgoz MB: The neonatal splice variant of Nav1.5 potentiates in vitro invasive behaviour of MDA-MB-231 human breast cancer cells. Breast Cancer Res Treat 101: 149-160, 2007.

35. Baptista-Hon DT, Robertson FM, Robertson GB, Owen SJ, Rogers GW, Lydon EL, Lee NH and Hales TG: Potent inhibition by ropivacaine of metastatic colon cancer SW620 cell invasion and NaV1.5 channel function. Br J Anaesth 113 (Suppl 1): i39-i48, 2014.

36. Gillet L, Roger S, Besson P, Lecaille F, Gore J, Bougnoux P Lalmanach $G$ and Le Guennec JY: Voltage-gated sodium channel activity promotes cysteine cathepsin-dependent invasiveness and colony growth of human cancer cells. J Biol Chem 284: 8680-8691, 2009.

37. Xing D, Wang J, Ou S, Wang Y, Qiu B, Ding D, Guo F and Gao Q: Expression of neonatal Nav1.5 in human brain astrocytoma and its effect on proliferation, invasion and apoptosis of astrocytoma cells. Oncol Rep 31: 2692-2700, 2014.
38. Nelson M, Yang M, Millican-Slater R and Brackenbury WJ: Nav1.5 regulates breast tumor growth and metastatic dissemination in vivo. Oncotarget 6: 32914-32929, 2015

39. Ozkucur N, Monsees TK, Perike S, Do HQ and Funk RH: Local calcium elevation and cell elongation initiate guided motility in electrically stimulated osteoblast-like cells. PLoS One 4: e6131, 2009.

40. Perike S, Özkucur N, Sharma P, Staroske W, Bläsche R, Barth K and Funk RH: Phospho-NHE3 forms membrane patches and interacts with beta-actin to sense and maintain constant direction during cell migration. Exp Cell Res 324: 13-29, 2014.

41. Ozkucur N, Perike S, Sharma P and Funk RH: Persistent directional cell migration requires ion transport proteins as direction sensors and membrane potential differences in order to maintain directedness. BMC Cell Biol 12: 4, 2011.

42. Roger S, Gillet L, Le Guennec JY and Besson P: Voltage-gated sodium channels and cancer: Is excitability their primary role? Front Pharmacol 6: 152, 2015.

43. Yang $M$ and Brackenbury WJ: Membrane potential and cancer progression. Front Physiol 4: 185, 2013.

44. Redmann K, Müller V, Tanneberger S and Kalkoff W: The membrane potential of primary ovarian tumor cells in vitro and its dependence on the cell cycle. Acta Biol Med Ger 28: 853-856, 1972.

45. Brisson L, Driffort V, Benoist L, Poet M, Counillon L, Antelmi E, Rubino R, Besson P, Labbal F, Chevalier S, et al: NaV1.5 Na channels allosterically regulate the NHE-1 exchanger and promote the activity of breast cancer cell invadopodia. J Cell Sci 126: 4835-4842, 2013. 